\title{
Three Ethical Issues in the Development of Public Genetic Health Policies in Africa
}

\section{Anton A van Niekerk}

Director, Centre for Applied Ethics, University of Stellenbosch, South Africa

*Corresponding author: Anton A van Niekerk, Director: Centre for Applied Ethics, University of Stellenbosch, South Africa, Tel: +27-21-8082055; Fax: +27-21-8083556; E-mail: aavn@sun.ac.za

Received date: July 25, 2014; Accepted date: November 27, 2014; Published date: December 02, 2014

Copyright: (c) 2014 Van Niekerk AA, et al. This is an open-access article distributed under the terms of the Creative Commons Attribution License, which permits unrestricted use, distribution, and reproduction in any medium, provided the original author and source are credited.

\begin{abstract}
It is of paramount importance that sensible and prudent public policies for the introduction and management of genetic research, technologies and therapies be adopted for countries on the African continent. The author agrees with Buchanan et al. when they claim that it is "unwise to consider the ethics of genetics only at the individual level. What matters is not merely the ethics of the individual scientist, physician or counsellor, but the broader questions of justice, of claims for freedom and for protection from harm, and our obligations towards future generations". What is therefore important, is the development of a "public and institutional policy on genetics" (Ibid.) that is adopted for the needs of, specifically, the people of Africa. The author delineates three such issues, and indicates some moral aspects that accompany their understanding as well as the challenges that they pose. The three issues are: (i) The kinds of genetic technologies that are appropriate for African needs, (ii) The lessons about public health policy to be learned from (especially South African) policymakers' appropriation of scientific expertise, (iii) Concerns about informed consent of patients and the competence of health care professionals in administering appropriate genetic remedies in African societies.
\end{abstract}

Keywords: Africa; Ethics; Genetics; Technologies; Policy makers; Informed consent

\section{Introduction}

Genetic knowledge and the possibility of genetic technologies are a sensitive topic in Africa. This is not only because this kind of knowledge has been abused by politicians and scientists in the pastand, of course, by the fact that there are alarming signs that old-style eugenics is apparently still looked upon favorably by even some modern day policy makers, such as those in Singapore, Malaysia and even China [1]. This is also not only because of the misguided and naive, though widely entertained idea that once we know a person's genetic make-up, we know everything there is to know about a person. It is, especially in Africa, a sensitive matter because genetics lies and functions at the foundations of family and ethnicity (including race, although the latter term is more related to biology than ethnicity, which normally rather refers to culture), two of the most powerful forces that determine human attitudes and emotions. Family in Africa is a central social construct in terms of which human identity is constituted and understood. Race, particularly in Africa, as also in many other parts of the world, is a genetic trait that has often been elevated to the central defining feature of a person's humanity, and is thus one of the most powerful tools for some groups of humans to disempower, discriminate against, humiliate and ultimately dehumanize fellow human beings. Racism is indeed the original form of the "genetic ghetto" into which, according to Buchanan et al. [1], people can sometimes be marginalized because of genetic knowledge and techniques-a ghetto from which the escape is mercifully progressing in our time, although it is far from complete.
Given the legacy of racism and the manifold of discriminatory perceptions and practices associated with the racist marginalization of the world's "people of colour" in the past, genetic science and technologies do indeed hold, for Africans, the threat of the introduction of what Eduardo Rivera-Lopez [2] calls "a new source of inequality". By "new genetic technologies" I refer to things such as genetic engineering, cloning, stem cell applications, life-extending biosciences, intelligence intensifiers, smarter interfaces to swifter computers, neural-computer integration, world-wide data networks, virtual reality, intelligent agents, swift electronic communication, artificial intelligence, neuroscience, neural networks, artificial life, offplanet migration and molecular nanotechnology. If the gains from the new genetic technologies will only become manifest proportionately to the relative wealth of, and therefore predominantly within the confines of the populations of the developed world, these new technologies hold the cumbersome promise of a new source of disadvantage and marginalization of the peoples of our part of the world where the burdens of misfortune, exploitation, poverty and disease threaten to stultify countries and communities into chronic maladjustment and regression. We ought therefore not to be surprised at widespread suspicions amongst Africans that genetic research and new emerging genetic technologies are, or could well be, no less than a new form of control over groups of people in the world who are allegedly "too numerous" and who are of no relevance to market economies [3].

Africa has indeed long been the victim of prejudice. Its patent current lack of resources and its, generally speaking, limited input into state of the art scientific research achievements, hold, anew, the threat of a kind of exclusion from the advantages of modern medicine. This might, in time, reinforce the prejudice against the continent-a prejudice which has in recent times, to add insult to injury, been 
exacerbated by the HIV/AIDS pandemic. H Nickens ${ }^{1}$ Nickens, the Human Genome Project runs the risk of creating a "new biologic underclass" [4] in as much as it runs the risk of buttressing prevailing biases, the belief in biological determinism and the tendency to draw unfounded distinctions between citizens on the basis of race and ethnicity. We shall return to this issue in the second section of the article.

It is exactly because of these dangers that it is of paramount importance that sensible and prudent public policies for the introduction and management of genetic research, technologies and therapies be adopted for countries on the African continent. I agree with Buchanan et al. when they claim that it is "unwise to consider the ethics of genetics only at the individual level. What matters is not merely the ethics of the individual scientist, physician or counsellor, but the broader questions of justice, of claims for freedom and for protection from harm, and our obligations towards future generations" [1]. What is therefore important, is the development of a "public and institutional policy on genetics" (Ibid.) that is adopted for the needs of, specifically, the people of Africa. My aim in the rest of this paper is to delineate three such issues, and briefly indicate some moral aspects that accompany their understanding as well as the challenges that they pose. The three issues are: (i) The kinds of genetic technologies that are appropriate for African needs, (ii) The lessons about public health policy to be learned from (especially South African) policymakers' appropriation of scientific expertise at a certain period of the history of that country (1999-2007), (iii) Concerns about informed consent of patients and the competence of health care professionals in administering appropriate genetic remedies in African societies.

\section{The kinds of genetic technologies appropriate for African needs}

Africa is not the source of the new genetic technologies, although Africa might play an important role in the future development of these technologies, particularly in as much as the African gene pool might harbour valuable information about the ancient and recent histories of our species. However, it is safe to claim that African societies will, especially at this stage of proceedings, be more inclined to be users and appliers, rather than developers, of these technologies.

Africa, in addition, and especially as far as resources for health care are concerned, is a very poor continent. Sub-Saharan Africa generates no more than $1 \%$ of the total wealth produced in the world. The buying power of all the countries south of the Sahara, excluding South Africa, in total just about matches that of a country such as Norway ${ }^{2}$. As has often been pointed out, Africa is the home of $15 \%$ of the world's population, lives on $1 \%$ of the global economy, and carries $70 \%$ of the world's HIV/AIDS burden [5]. The 2010 Health Expenditure Report indicates that $84 \%$ of annual global health expenditure is directed to $18 \%$ of the world's population-the so-called 80-20 divide.

The United States spends above 50 percent of the total health care expenditure in the world. This US expenditure is in fact spent on only $5 \%$ of the world's population. In this current year (2014), the USA spends more than twice as much per capita on health care (\$8745) than the average developed country does $(\$ 3484)[6,7]$. On the one hand, it holds the danger, as I have hinted at earlier, of perpetuating the gross global inequalities in terms of health care provision between Africa and the West-a situation that, of itself, requires increasing moral assessment, as has been done in the recent work of Solly Benatar and others [8-10]. On the other hand, Africa's limited resources compel us on this continent to be quite selective and discriminate about those technologies that ought to be deemed appropriate for our most urgent needs. Given Africa's resources crisis, ideas about the possibility of all kinds of genetically induced personal enhancements are far removed from the urgent and immediate health care realities that policy makers have to face on a daily basis, given the prohibitive costs that such research or technologies might imply. This particularly applies to the public health sector which, even in a country such as South Africa (a considerably more wealthy country than most other African states) caters for more than $80 \%$ of the population. While there has been a decisive improvement in membership of medical aid schemes-2013 figures show that 9.7 million South Africans are now members of medical aid schemes-in a population of 52.98 million, at $18.4 \%$ of the population, this figure is still woefully inadequate [11]. It is as yet unclear how these schemes will respond to genetic therapies. There is, consequently, very little scope, in the short to medium term, for exotic genetic technologies to become prevalent in African societies.

That does, however, not mean that genetic medicine is irrelevant for African conditions and needs. In fact, it is quite foreseeable that certain kinds of research are very relevant for Africa. This particularly pertains to research on the genetic basis of Africa's main health care challenges, viz. AIDS, tuberculosis and malaria.

As far as genetic therapies are concerned, it would, in this respect, not be very useful or morally relevant to insist on the therapy/ enhancement distinction, since a positive outcome of genetic research into the possibility of boosting people's immune systems, as envisaged by Kitcher [12], would be of existential importance to Africans in view of the current AIDS pandemic. Kitcher claims that "we are no more playing God by altering people genetically so that they have greater immunity than we are when we give them vaccinations" [1].

The therapy/enhancement distinction, in any case, can sometimes be quite misleading, particularly when it comes to AIDS treatments. Nils Holtug provides an appropriate example of this in the following case:

"Jane is infected with HIV. Her immune system is starting to give in and she is about to develop AIDS. Fortunately, there is a new kind of gene therapy available - call it therapy A-that will boost her immune system and bring it back to normal, so that she will in fact never develop AIDS. By performing the therapy, we are correcting her (or her immune system). Now consider Helen. She has not yet been infected with HIV, but she is a haemophiliac and, since blood reserves at the hospital have not been screened for HIV, we know it is only a matter of time before she is infected, unless she receives a new kind of gene therapy-call it therapy B-that will make her immune. (Unfortunately therapy B only works on haemophiliacs, so it cannot be used on Jane.) By performing the therapy, we are enhancing her (or her immune system) since we are giving her a desirable property that people do not normally (or naturally) have. The point is that, intuitively, it does not seem more problematic or less urgent to perform therapy B on Helen than to perform therapy A on Jane. But,

1 See Nickens (1996: 59-78). I also draw on Benatar's (1999: 170-171) discussion of this point.

2 Personal communication by a colleague in the Dept. of Economics at Stellenbosch University. 
according to the view that enhancing is more dubious, it must be so (since the cases are relevantly similar in other respects). Thus, the intuitive case for this view is not as clear-cut as it initially seems" [13].

The first moral challenge to public policy on genetic health in Africa is therefore to support, encourage and embrace research and technologies that hold important promise for African conditions and needs. Benatar writes in this respect: "When biotechnology is used to mass-produce drugs such as insulin and vaccines, to develop more resilient crops, to increase the efficiency of food production, or in other ways that improve the lives of individuals, this is uniformly welcomed, especially if costs are reduced and access increased for all to drugs, vaccines and food. However, it is possible, perhaps even likely, that such advances may not be available to those in poor countries because they are too costly - as for example with new drugs for treating HIV infection" [3]. This is a responsibility not only for African governments and science funders, but also for benevolent governments and sponsors of African health needs in the developed world. The reference to HIV infection in fact also leads us to our next point.

\section{The lessons about public health policy to be learned from (especially South African) policymakers' appropriation of scientific expertise at the turn of the century}

One of the most important lessons to be learned from the South African Government's response to the AIDS epidemic in South Africa during the years 1999 to 2007, is how highly problematic the relationship between internationally accredited science and policymakers may become. It is a widely known and embarrassing fact that many members of the ruling party in South Africa, at the apparent instigation of the then President and the Minister of Health, for a long time not only seemed to deny the urgency and catastrophic nature of the HIV/AIDS pandemic in South Africa, but even seemed to embrace the views of dissident scientists such as Duesberg and Rasnick [14] who deny that AIDS is caused by the HI virus. In fact, on March 8, 2003, the then Minister of Health, Dr. Manto Tshabalala-Msimang appointed Dr. Roberto Giraldo as an adviser to the Government. Giraldo is on record as publicly claiming that "the transmission of AIDS from person to person is a myth... an assumption made without any scientific validation...malnourishment is at the centre of its [i.e. AIDS'] progression" [15]. These claims were echoed by pres. Mbeki in an interview with New Straits Times on February 16, 2003. The aforementioned Minister of Health, in turn, was noted as saying that AIDS does not deserve special attention in South Africa [16]-a country where, during the period in which she held office, more than $25 \%$ of the adult population (and $11.6 \%$ of the total population) were HIV positive, where about 360000 people died in 2002 because of AIDSrelated disease, an estimated 660000 children had been orphaned by AIDS, where 1500 people were infected every day and where it was conservatively estimated that 600 people died of AIDS-related disease every day! (UNAIDS Epidemic Update 2002) [17] ${ }^{3}$. She also offered to go to jail in solidarity with the then denialist MEC for Mphumalanga, ms. Sibongile Manana, who continued to defy court orders that an NGO called GRIP be allowed to provide antiretroviral drugs to rape victims in the Rob Ferreira Hospital in Nelspruit [18,19].
Unfortunately, a lot of the hesitance and denial about AIDS in South Africa were seemingly inspired by the leadership, or lack of leadership, from the previous South African president Thabo Mbeki (1999-2007) on the matter. One can only speculate about the real reasons for this surprising and alarming phenomenon. It clearly has, amongst others, to do with a deep-seated scepticism of the scientific facts about the nature of the epidemic, fuelled by the influence of dissident scientists like Rasnick, Geshekter and Duesberg who question whether HIV causes AIDS at all [20-22]. It became clear that the South African President had been under the influence of the dissidents for a long time-he even appointed some of them to a "task group" to "do research" to establish the relationship between HIV and AIDS-and had been exerting a very strong influence on the official position taken on these matters by the Minister of Health and other prominent members of the government and the ANC. In an article that he wrote, Pres. Mbeki asked a number of questions about the apparent differences between the way AIDS presents in Africa and in other Western countries and claimed that "we will not, ourselves, condemn our own people to death by giving up the search for specific and targeted responses to the specifically African incidence of AIDS" [23]. He claimed that this search for "targeted responses" had been viewed as a "criminal abandonment of the fight against HIV/AIDS". $\mathrm{He}$ continued: "Some elements of this orchestrated campaign of condemnation worry me very deeply. It is suggested, for instance, that there are some scientists who are 'dangerous and discredited' with whom nobody, including ourselves, should communicate or interact. In an earlier period in human history, these would be heretics that would be burnt at the stake!" He then continued to sing the praises of these discredited scientists (i.e. people like Duesberg and Rasnick).

What exactly the reason for Mbeki's sympathy with these dissidents was, is not entirely clear. However, he did give a hint as to his motive in this regard in a widely reported address to the University of Fort Hare in 2001. I quote Mbeki's words from this latter report: "Thus does it happen that others who consider themselves to be our leaders take to the streets carrying their placards, to demand that because we are germ carriers, and human beings of a lower order that cannot subject its [sic] passions to reason, we must perforce adopt strange opinions, to save a depraved and diseased people from perishing from self-inflicted disease...Convinced that we are but natural-born promiscuous carriers of germs, unique in the world, they proclaim that our continent is doomed to an inevitable mortal end because of our unconquerable devotion to the sin of lust" [24]. From these words it seems that his and other members' of the governing party's denial sprang, not only from scepticism about accepted scientific facts, but also from concerns about what these facts imply about continued racism as well as the sexual mores of African people.

Science is not value free, and is not exempt from criticism. Public policy on health care ought to, as far as possible, be informed by sound scientific evidence. On the basic facts about the HI virus and its manner of transmission there is, however, overwhelming international scientific consensus - established knowledge that is highly inappropriate for policy makers, whose decisions determine the health care options of desperately ill people, to doubt or even ridicule, as has been done in South Africa during the indicated period. The AIDS debacle in South Africa simply shows to what extent people's real health care needs can be compromised by hesitant, denialist politicians

\footnotetext{
3 According to UNAIDS estimates, there were 6.3 million HIV infected people living in South Africa at the end of 2013, of which 3.5 million are females aged 15 and upwards, and 2.4 million are males of the same age, while the remaining 400000 are children under 15 years [22].
} 
who draw on the publicity seeking ambitions of opportunist crackpots. This constitutes a - possibly the-major moral problem in the understanding and management of the AIDS problem in South Africa.

It must, in all fairness, be pointed out that much has changed about the management of South Africa's HIV problem since Dr. Aaron Motsoaledi took over the helm as Minister of Health since 2008 Under his leadership, enormous strides have been made to get people tested for HIV and started on antiretroviral treatment. South Africa currently has the largest HIV treatment program in the world. But in spite of this, the HIV prevalence situation in South Africa is still a cause for alarm. According to the South African National HIV Prevalence, Incidence and Behaviour Survey of 2012, South Africa still has an HIV prevalence of $12.2 \%$, which is an increase over the 2008 estimate (p.108) [25]. "The estimated prevalence increase of about 1.2 million between 2008 and 2012 is likely a result of new HIV infections that occurred over the past four years and reduced mortality among those living with HIV and AIDS due to the large scale roll-out of ARV's" (Ibid.)

One is thankful that, after years of activism by organizations such the Treatment Action Campaign, extended litigation and international pressure, the South African government has, at last, agreed to provide antiretroviral treatment in the public health sector. There are, however, still alarming indications that the process is unfolding much too slowly.

As suggested earlier, the hesitation and denial of the earlier South African leadership is, to a certain extent, understandable, though hardly pardonable. Just at the time when an intellectually gifted leader such as Thabo Mbeki was ready to launch his idea of an "African Renaissance" $[26,27]$ and to promote Africa as the continent of the $21^{\text {st }}$ century, they ended up with the challenge of handling one of the severest health nightmares a politician can imagine. In the process, as is persuasively argued by Van der Vliet, all the existing prejudices against Africa were reinforced, if not exacerbated. One of the cruel effects of AIDS, as was realized from the outset, is that it often afflicts people who are already victims of prejudice and discrimination: homosexuals (initially), drug addicts, eventually the poor and the wretched. In this regard, "the coincidence of a new disease, in marginalized communities, in troubled and insecure times, was a recipe for a new wave of prejudice" [28].

This reinforcement of old prejudices has now shifted from individuals and communities to a whole continent. AIDS is increasingly called "the African epidemic" [29]. This inevitably fosters a politicization of the discourse about the pandemic which, in turn, complicates its effective management considerably. In a rather inflammatory article, Simon Watney articulates the kind of resentment that the identification of AIDS and "Africanness" have fostered in many intellectual and leadership circles on the continent:

“...Africa has been effectively demonized in a post-colonial discourse of perpetual catastrophe and unnatural disasters. This undifferentiated apocalyptic Africa has proved an ideal site in which to find and "see" disease. "African AIDS" thus condenses ancient fears concerning contagious disease, together with vengeful fantasies concerning "excessive" sexuality, understood in essentially premodern terms as both the source and the cause of AIDS...The racism and homophobia which Western culture has visited on racial and sexual minorities for millenia now threaten to turn back on heterosexuals themselves, in their seeming refusal and inability to acknowledge the realities of HIV infection and disease. It would appear that we are witnessing a fundamental reorganisation of Western racism, as the constitutive colonial analogy between race and class is dissolved, and African blackness is reconceptualised as an analogue of the sexually perverse" [30].

Although some of these emotional allegations may not be devoid of all truth, they are not very helpful when we are confronted with the question of how, in practical terms, to go about assisting in the relief of the suffering of real people living with HIV/AIDS. One of the main complexities facing the management of the disease in Africa, is, therefore, this kind of consistent politicization of the discourse about AIDS-a politicization which raises the level of inflammatory rhetoric and moral outrage about the injustices of the universe and the global economy, but which is not very helpful when practical programs are to be devised for the help of ordinary, not always politically conscious sufferers: the people who are the real victims of the denial and hesitant leadership of those who have it in their power to do something about the crisis in Africa.

It is, therefore, of paramount importance for the political leadership in Africa to acknowledge, for once, the reality of the crisis and to stop obfuscating its understanding or management by undue politicized rhetoric about an alleged social outrage which, essentially, is a health problem and can significantly be curbed if primarily addressed as such. In addition, it is similarly important to seek optimal partnerships and co-operation with the pharmaceutical multinationals as well as other supportive governments who have it in their power to facilitate the provision of essential anti-retroviral drugs at more affordable prices. The same would naturally be applicable to future genetic therapies that may become available, and that may be of great significance to the treatment of AIDS and other diseases afflicting the African continent. This has in fact happened in South Africa on a significant scale and is evidenced by the large and successful ART program in South Africa.

One simple lesson has to be learned from this debacle as it reflects on genetic science and its possible effects on Africa: make sure of the established scientific facts, be advised by and find a good working relationship with the credible scientific community who are able to advise wisely and cautiously. Without such a modus operandi, African policy makers deny themselves the opportunity of eliciting the best that science can offer for their subjects, and run the risk of irreparably harming, in addition to their subjects, also their own credibility locally and in the rest of the world.

\section{Concerns about informed consent of patients and competence in administering appropriate genetic remedies in African societies}

In delineating the third moral issue related to the implementation of new genetic technologies in Africa, I wish to quote and comment on a remark by Buchanan et al. [1]:

"The accumulation of information regarding risks posed by genetic defects is rapidly accelerating and will increase the volume of useful service manifold. This is not information easily absorbed by most patients. Even assuming maximum receptiveness and attentiveness to the explanations of physicians and counsellors-an unrealistically optimistic assumption given what is at stake in reproductive decisionspatients must acquire familiarity with genetic diseases they may have never heard of before and must appreciate the significance of the statistical data about estimating the risks. Providing this information without sufficient opportunity for absorption, questioning, and 
Page 5 of 6

repetition is worse than useless, for in creating fear and even panic it can harm the patient and inadvertently steer him or her toward poor decisions" [1].

Two remarks are opportune in this regard. The first concerns patient competence, and the second health care worker competence as regards genetic counselling and therapies.

If what the authors in the above quote assert is true of patients in the USA-arguably the society where the level of public informedness about health care is the highest in the world ${ }^{4}$-then we might well foresee serious problems to communicate effectively with Africans about the nature and efficacy of genetic medicine. The reason is not that Africans are generally unintelligent or uninformed, but the simple fact that general levels of education in Africa are considerably lower than in the West.

Illiteracy, for example, is a huge problem even in South Africa, Africa's most developed economy. If literacy is defined as the ability to read, write and numerate (normally conditional on 7 years of schooling), then according to the 2012 General Household Survey, only $7 \%$ of the adult population of South Africa is illiterate. However, this figure is supposedly a far from accurate reflection of true literacy rates in South Africa due to the way in which literacy itself has been "defined and measured" [31]. The accuracy of this figure is also called into question when compared to earlier figures which documented $41 \%$ of the adult population of South Africa as illiterate [32].

This situation poses considerable challenges to effective communication with Africans about genetic medicine. Concerns about proper conceptions of informed consent in Africa ought to be considered in conjunction with this problem. Informed consent in the African context cannot be modelled on the way it typically functions in the West. The concept of a person, in many African communities, does not necessarily presuppose the stark atomistic individualism that accompanies conceptions of informed consent in the developed world. People from these communities live their lives and make sense of their world in much closer connection and correlation with family and kinship ties. The concept of the family itself attains a distinctive extended meaning in most African societies. Communality and interdependence play a much more important role. In such a context, decisions are seldom taken on a purely individualistic basis; family members and authority figures are best expected to become involved. This is not an unproblematic phenomenon, since it cannot uncritically be assumed that the input of all these participants, particularly authority figures, is really based on adequate knowledge and the best interest of the patient. What we can be certain of, is that the fact that the treatments we are talking about are genetic, and have implications for offspring and the like, is bound to complicate the process of acquiring informed consent for genetic medicine in Africa considerably.

In a Masters dissertation attained at the University of Cape Town, Paul Roux, a paediatrician at the Red Cross Children's Hospital in Cape Town, argues persuasively for the thesis "that the process of informed consent, although appropriate in Africa as an exercise in the recognition of autonomy, when applied in the case of African women may have the unexpected and deleterious effect of isolating her from a traditional support base and enhance the likelihood of non-disclosure of HIV status, and should therefore be adapted to meet the needs of this special situation" [33]. This "adaptation", according to the author, mainly entails involving the family much more in the process of obtaining consent. Roux has, in particular, found that if the mother of an HIV infected young woman is available, it normally works quite well to inform her of the problem as soon as possible and to utilise her standing when it comes to dealing with the rest of the family and the community. In the absence of a mother, an older woman that is trusted by the patient can normally play a similar role quite successfully. Roux argues that his research has shown that this approach greatly contributes to a lesser risk of stigmatization. His findings, based on empirical research done in an antenatal HIV clinic at the hospital, confirm what has been argued in the previous paragraphs.

My last remark concerns the competence of the health workers who have to administer both counseling and possible therapies in the African context. Buchanan et al., write the following about the situation in the USA: "Most physicians in the United States lack the training needed to provide even rudimentary genetic counseling, and patients must rely on clinical geneticists and genetic counselors. Yet the supply of well-trained professionals in this field is so limited that, in one estimate, if the cystic fibrosis gene were the subject of population-wide screening, all the professionals' working hours would be taken up with the counseling necessary for a thorough work-up" [1]. If these authors are (probably rightly) concerned about the availability of adequately trained physicians and/or other professionals to meet the challenge posed by procedures such as genetic screening in the USA, we can be assured that the situation in Africa will be infinitely worse.

This raises the question whether there is any real prospect that Africans' lives will, in the near to medium future, be tangibly affected by genetic health care. It does not seem probable. There are serious constraints on the wholesale inclusion of Africa in the mainstream of developments in genetic medicine. That ought nevertheless not to prevent authorities and medical researchers and practitioners in Africa from acquainting themselves as much as possible with the possibilities opened up by the recent developments, and to pursue as far and as cost-effectively as possible opportunities for making the new technologies available to Africans who can clearly benefit from them.

\section{References}

1. Buchanan A, Brock DW, Daniels N, Wikler D (2000) From chance to choice: Genetics and justice. Cambridge University Press, Cambridge.

2. Rivera-López E (2002) Ethics and genetics in Latin America. Developing World Bioethics 2: 11-20.

3. Benatar SR (1999) A perspective from Africa on human rights and genetic engineering. In Burley J (Ed.), The genetic revolution and human rights (The Oxford Amnesty lectures). Oxford University Press, Oxford, 159-189.

4. Nickens H (1996) The genome project and health services for minority populations. In Murray TH, Rothstein MA, Murray RF (eds.): The Human Genome Project and the future of health care. Indiana University Press, Bloomington, Ind, 59-78.

5. WHO HIV/Aids Fact sheet (2014).

6. Americans spend over twice as much per capita on healthcare as the average developed country does (2014).

4 I was, for example, during a visit to the US, struck by the number of health care advertisements during peak hour television - a revelation, not only of the level of commodification of health care, but specifically of the informedness of the general population in health care matters. 
Citation: Van Niekerk AA (2014) Three Ethical Issues in the Development of Public Genetic Health Policies in Africa. J AIDS Clin Res 5: 399. doi:10.4172/2155-6113.1000399

Page 6 of 6

7. Healthcare spending around the world, country by country (2014).

8. Benatar SR (2001a) Global issues in HIV research. Journal of HIV Therapy 5: 89-91.

9. Benatar SR (2001b) Commentary: Justice and medical research: a global perspective. Bioethics: 333-340.

10. Benatar SR, Daar AS, Singer PA (2003) Global health ethics: the rationale for mutual caring. International Affairs 79: 107-138.

11. Statistics South Africa (2013) General Household Survey 2013.

12. Kitcher P (1996) The lives to come. Simon \& Schuster, New York.

13. Holtug $\mathrm{N}$ (2012) Creating and patenting new life forms. In: Kuhse H, Singer P (Eds.) A companion to bioethics. Blackwell, Oxford, 235-244.

14. Duesberg PH, Rasnick D (1998) The AIDS dilemma: drug diseases blamed on a passenger virus. Genetica 104: 85-132.

15. Msomi S, Munusamy R (2003) Manto appoints Aids dissident as adviser.

16. Kindra K (2003) What's so special about Aids? Mail \& Guardian 2-3.

17. UNAIDS Epidemic Update (2002).

18. Quintal A (2003) Go directly to jail UDM tells Manto.

19. Kühne I (2003) Dié LUR se word is wet. Rapport, 16 Maart: 9

20. Duesberg PH (1998) Inventing the AIDS virus. Regnery, Washington D.C.

21. Rasnick D (2000) Talked with President Thabo Mbeki.

22. UNAIDS HIV and AIDS estimates (2013)
23. Mbeki T (2000) Reciting comfortable catechisms on AIDS is not good enough. The Sunday Times.

24. Forrest D, Streek B (2001) Mbeki in bizarre AIDS outburst. Mail \& Guardian 26: 4-5.

25. Statistics South Africa (2012) General Household Survey 2012.

26. Mbeki T (1998) Africa: The Time has Come: Selected Speeches. Cape Town: Tafelberg \& Mafube.

27. Makgoba MW (Ed.) (1999) African Renaissance: The New Struggle. Mafube \& Tafelberg, Cape Town.

28. Van der Vliet V (1996) The Politics of AIDS. London: Bowerdean Publishing Company.

29. Caldwell JC (2000) Rethinking the African AIDS Epidemic. Population and Development Review 26: 117-135.

30. Watney S (1989) Missionary Positions: AIDS, 'Africa' and Race. Critical Quarterly 31: 46-62.

31. Pretorious S (2013) SA's real level of literacy.

32. Bot M, Wilson D, Dove S (2000) The Education Atlas of South Africa. Johannesburg: Education Foundation.

33. Roux P (2001) Informed Consent for Voluntary Counselling and Testing for HIV Infection in South African Mothers and Children: An Assessment of Burdens and Consequences and an Argument for a Modification in the Process of Informed Consent. Unpublished M.Phil. (Bioethics) Dissertation, University of Cape Town. 